\title{
THERMAL, STRUCTURAL AND ORPHOLOGICAL ANALYSIS OF BCG POWDER FOR SOFCs
}

\author{
A.Senthil Kumar ${ }^{1}$ \\ \{Email_ask.apsc@psgtech.ac.in ${ }^{1}$ \} \\ Department of Applied Science (Physics),PSG College of Technology, Coimbatore-04, TN ${ }^{1}$
}

\begin{abstract}
Solid oxide fuel cells (SOFCs) are being considered as one of the gifted material for the conversation of chemical energy into electrical energy. This SOFC will give high efficiency energy conversion and low environmental pollution impact. In the current research work, gadolinium doped barium cerate (BCG) based electrolyte powder was systematically prepared through Co-precipitation Method. The crystalline nature of powder sample was analysed through X-Ray diffractometer and to find the crystallite size. HRTEM analysis was performed to know the particle size distribution and were reported.
\end{abstract}

Keywords: Barium cerate (BCG), Electrolyte. DSC, XRD, HRTEM, Fuel cells.

\section{INTRODUCTION}

Solid oxide fuel cells (SOFCs) are considered as an best energy conversion device that produces electrical energy by means of electrochemical process by the combination of an oxidant at one end and a fuel at the other end across an ionic conductor called electrolyte. There are two types of SOFC available based on the type of electrolyte material chosen, the very foremost one is an electrolyte from oxygen ion conductor and the second is a proton conducting electrolyte. In the recent decades, many researchers have made an effort in focusing the research work in the field of fuel cell (SOFC) containing oxygen ion conducting electrolyte. In general, the operating temperature of SOFCs are studied at high temperature between $800^{\circ} \mathrm{C}$ to $1000^{\circ} \mathrm{C}$. State of art like Yttrium stabilized $\mathrm{ZrO}_{2}$ (YSZ) has been studied extensively by many researchers and considered as one of the best solid electrolyte materials. Whereas this YSZ based electrolytes have shown low ionic conductivity when operated at temperatures of $1000^{\circ} \mathrm{C}[1]$.

Higher Operating temperatures of solid oxide fuel cell may lead to various issues in the fuel cell system, such as interconnectors and chemical instability of the components. This higher temperature operation of any fuel cell system is essential be reduced under $800^{\circ} \mathrm{C}$ and the ionic conductivity of an electrolyte used in the system must be increased for commercialisation of fuel cell energy conversion worldwide. Hence, it is essential to develop a suitable SOFCs electrolyte material which operate at transitional temperatures below $800^{\circ} \mathrm{C}$. Practically this lower operating temperature of any electrolyte material is possible and achieved by using a suitable electrolyte powder with dual phase morphology for higher ionic conductivity [2]. 


\subsection{Solid Electrolyte}

The solid electrolyte materials placed in between cathode and anode is measured as a main component for the conduction of oxide ion and to complete the overall electrochemical reaction. In this type of solid electrolyte, oxygen ion conduction takes place from which the oxide ions $\left(\mathrm{O}^{2-}\right)$ migrate from the air electrode(cathode) side to the fuel electrode(anode). In this type of electrolyte materials, the charge flow occurs due to the migration of oxide ions through the existing crystal lattice.[1] Moreover, in these crystal lattice the development of dual phase crystal structure such as fluorite and perovskite structure is observed for high ionic conductivity. Practically, every fuel cell system are being developed from yttrium stabilized zirconia (YSZ), because of having an high oxide ionic conductivity at low temperature operation and also shown the required chemically solidity at higher operating temperature [3].

\subsection{Intermediate temperature}

Significant research work has been made to address the reduction of operating temperature of SOFC using different electrolyte materials to achieve the required higher ionic conductivity [4]. Doped Ceria based electrolyte materials with its Fluorite and perovskite structure has been considered as an electrolyte for SOFC. Like Yettria stabilised Zirconia, doped ceria based electrolyte material was studied extensively to increase ionic conductivity at lowest operating temperature below $800^{\circ} \mathrm{C}$. Rare earth oxide doped ceria with lower valency cations like gadolinium, samarium can remarkably increase the ionic conductivity of an electrolyte operated below $800^{\circ} \mathrm{C}[5]$.

\section{EXPERIMENTAL METHOD:}

The BCG electrolyte powder of gadolinium doped barium cerate has been prepared efficaciously using a simple chemical method called coprecipitation process. Cerium nitrate hexahydrate and Barium nitrate powders were taken in beakers and gets dissolved in $50 \mathrm{ml}$ of dis. water separately. Gadolinium oxide powder was taken in another beaker and get dissolved simultaneously in concentrated $\mathrm{HNO}_{3}$ by roasting in hot plat kept in a beaker separately and continuously stirred thoroughly until gets dissolved entirely. The fully dissolved solution was then slowly mixed together for 10 minutes to get clear solution. Ammonium hydroxide solution was slowly added into the clear solution to form the flakes like precipitate.

The $\mathrm{pH}$ value in the solution was maintained up to 11 and stirred well in a magnetic stirrer at an rpm rate of 500 for 30 minutes. 10\% of Poly Ethylene Glycol (PEG) solution was further added into the mixer. PEG solutions act as an excipient (fillers) to reduce the agglomeration in the prepared solution and allowed for drying. The gained precipitated solution was then filtered using filter paper and further kept inside oven for about 9 hours drying at $95^{\circ} \mathrm{C}$ [3]. The flakes like precipitate were formed, grained and calcinated at three different temperature called $700^{\circ} \mathrm{C} 800^{\circ} \mathrm{C}$ and $900^{\circ} \mathrm{C}$ for 5 hours to obtain the dry powder.

Thermal analysis was done for the dried powder using TA Instruments to know its phase formation temperature and confirmed. Diffraction studies was performed to determine their crystallinity, purity of phase formed in the as-prepared powder. HRTEM analysis was 
performed for the as prepared gadolinium doped ceria based powder to ascertain their particle size distribution $[4,5]$.

\section{RESULT AND DISCUSSION:}

\subsection{Thermal Analysis:}

Thermal analysis was performed using Differential scanning calorimetry (DSC) for phase investigation of Gadolinium doped ceria based (BCG) powders calcined at $700^{\circ} \mathrm{C}, 800^{\circ} \mathrm{C}$ and $900^{\circ} \mathrm{C}$ respectively for $5 \mathrm{hrs}$. TA Instruments Differential scanning calorimeter was used to do this thermal analysis. The scanning of the powder was carryout from $30^{\circ} \mathrm{C}$ to $500^{\circ} \mathrm{C}$ temperature range at a constant heating rate of $5^{\circ} \mathrm{C}$ per minute [6]. Differential scanning calorimetry results were shown in figure.1. From curve (a) it was understood that, the barium loss was much higher when calcined at $700^{\circ} \mathrm{C}$. From curve (b) it was understood that, the barium loss was comparatively lower when calcined at $800^{\circ} \mathrm{C} \mathrm{[7].}$

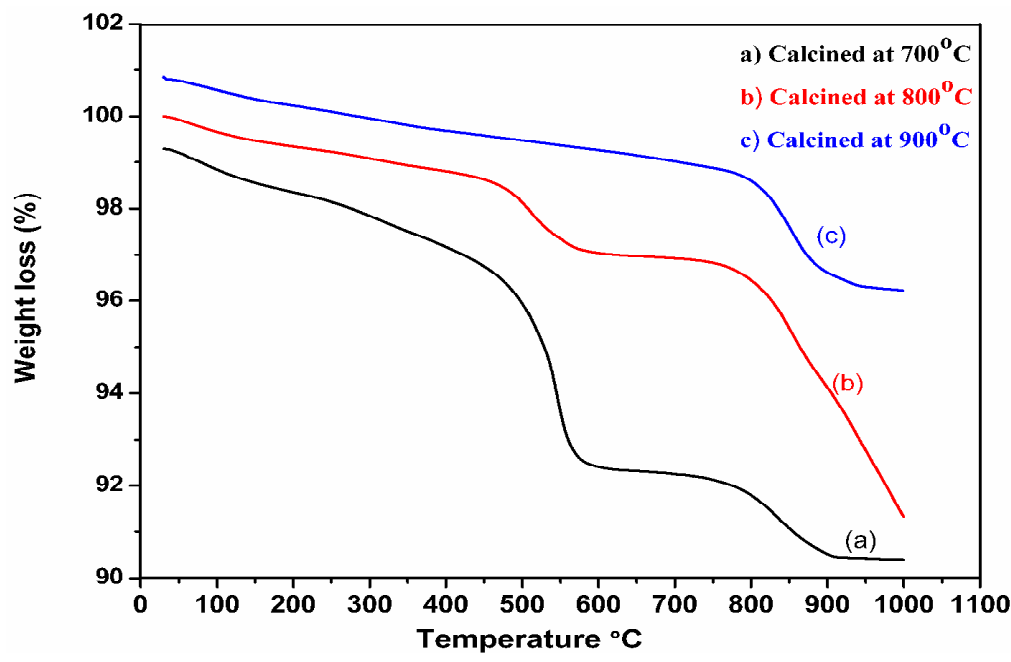

Fig.1 DSC patterns for BCG powder calcined at $700^{\circ} \mathrm{C}, 800^{\circ} \mathrm{C}$ and $900^{\circ} \mathrm{C}$ for $5 \mathrm{hrs}$.

From curve (c) it is understood that the barium loss is further reduced when calcined at $900^{\circ} \mathrm{C}$. From this DSC analysis results, calcinations temperature for gadolinium doped ceria based powder was identified as $900^{\circ} \mathrm{C}$ with the minimum loss in the barium content and can effectively retain the required phase for better ionic conductivity [8].

\subsection{X-Ray Powder Diffraction (XRD) Analysis:}

The structural characteristic analysis, the phase purity and lattice parameters were calculated by using Shimadzu powder X-Ray powder diffraction analyser. The results of the XRD analysis were shown in figure.2. It was identified that the powder sample calcined at $900^{\circ} \mathrm{C}$ shows the required single cubic phase and orthorhombic perovskite-type structure (PDF\#-822425 for Pmcn space group) and no impurity phase was detected in plane (200) of as prepared powder sample. 


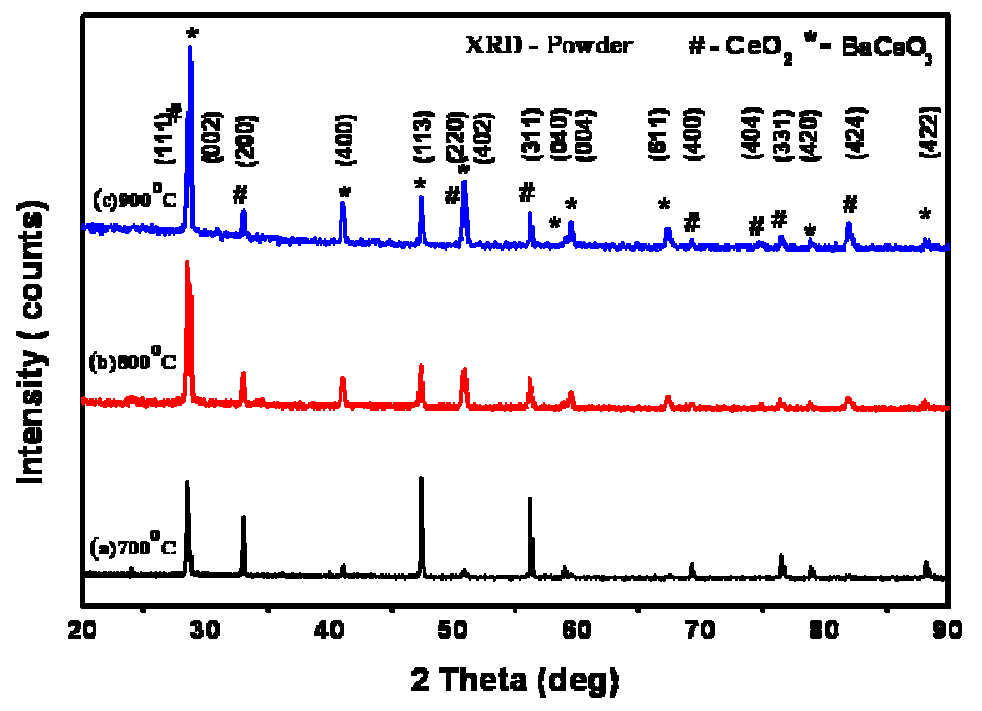

Fig.2 XRD crystalline pattern for powder heated at $700^{\circ} \mathrm{C}, 800^{\circ} \mathrm{C}$ and $900^{\circ} \mathrm{C}$ for $5 \mathrm{hrs}$.

From this XRD results, it was understood that the powder calcined at $900^{\circ} \mathrm{C}$, shows the required phase. The reflexes at (l $\left.\begin{array}{lll}0 & 2\end{array}\right),\left(\begin{array}{lll}4 & 0 & 0\end{array}\right),\left(\begin{array}{lll}1 & 1 & 3\end{array}\right),\left(\begin{array}{lll}4 & 0 & 2\end{array}\right),\left(\begin{array}{lll}0 & 4 & 0\end{array}\right),\left(\begin{array}{lll}0 & 0 & 4\end{array}\right),\left(\begin{array}{lll}6 & 1 & 1\end{array}\right),\left(\begin{array}{lll}4 & 2 & 0\end{array}\right)$ and $\left(\begin{array}{lll}4 & 2\end{array}\right)$ shows the barium cerate cubic structure [3,9]. Similarly, it can be seen that $\left(\begin{array}{lll}1 & 1 & 1\end{array}\right)$, (2 00 0), (2 20 0), (3 11 1), (4 $\left.\begin{array}{lll}0 & 0\end{array}\right),\left(\begin{array}{lll}4 & 0 & 4\end{array}\right),\left(\begin{array}{lll}3 & 3 & 1\end{array}\right)$ and $\left(\begin{array}{lll}4 & 2 & 4\end{array}\right)$ cerium oxide, perovskite-type structure [14]. The diffraction peaks position of the BCG powder is determined from the distance between parallel planes of atoms. Hence, the powder calcined at $900^{\circ} \mathrm{C}$ was found as a good choice of electrolyte powder for sofc application $[10,11]$.

\subsection{HRTEM Analysis:}

High resolution transmission electron microscope - HRTEM image of BCG powder calcined at $900^{\circ} \mathrm{C}$ was shown in figure 3 . The JEOL JEM 2100 HRTEM Analyzer was systematically used to record the image of the powder sample. The internal morphology of BCG powder in the form of nanoparticles was clearly observed and found to be nearly spherical with slight agglomeration formed $[12,13]$. The particle size distribution for the as prepared BCG powder was found to be around $50 \mathrm{~nm}$. The size of BCG nanoparticles decreased with increase in calcination temperature of then powder to $900^{\circ} \mathrm{C}$ for 5 hours [15]. Meanwhile, the size of BCG nanoparticles decreased when compared to the samples prepared at $700^{\circ} \mathrm{C}$ and $800^{\circ} \mathrm{C}$. Hence the $\mathrm{BCG}$ powder calcined at $900^{\circ} \mathrm{C}$ can show the development of nanoparticle as required for better ionic transport during the migration of oxide ions. 

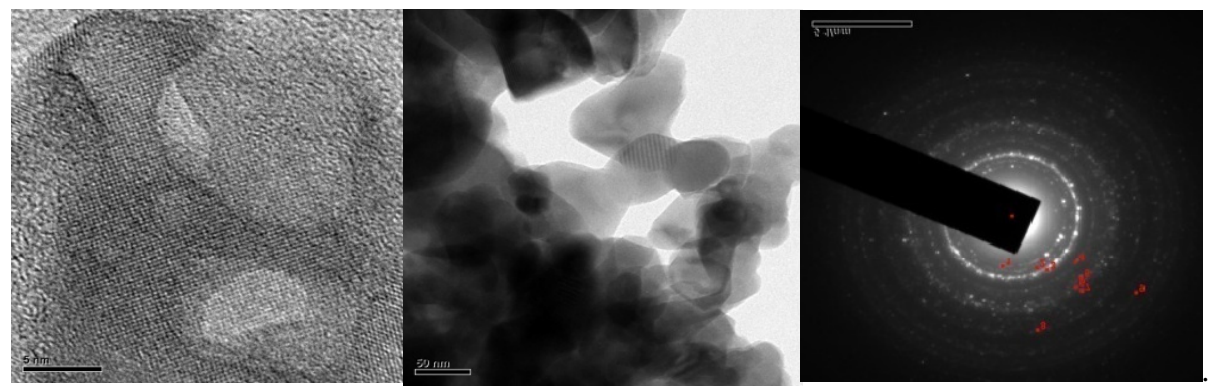

Fig.3HRTEM Image for BCG powder calcined at $900^{\circ} \mathrm{C}$ for $5 \mathrm{hrs}$.

The HRTEM image of as-prepared BCG nanoparticles were shown in Figure 3. The typical crystallite magnitude developed in calcined BCG nanocrystals was found to be around $50 \mathrm{~nm}$. BCG nanoparticles are observed as spherical size in the range of 20-50 $\mathrm{nm}$ and aggregate to arrangement of clusters in the powder sample [16]. Hence, the powder calcined at $900^{\circ} \mathrm{C}$ was found as a good electrolyte [17].

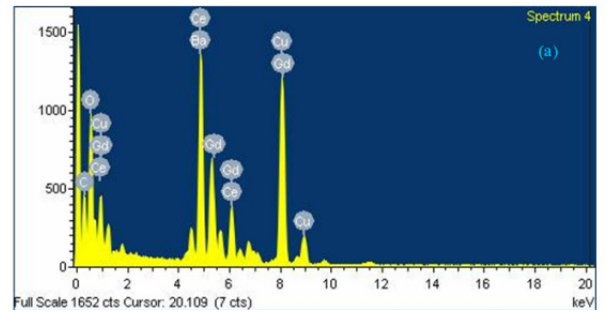

Fig.4 EDS spectrum of BCG powder calcined at $900^{\circ} \mathrm{C}$ for $5 \mathrm{hrs}$.

The energy dispersive spectrum (EDS) analysis for the BCG powder calcined at $900^{\circ} \mathrm{C}$ shows the weight and atomic percentage of all the precursor elements existing in the compound $[18,19]$. Fig.4 shows the energy dispersive spectrum of as prepared BCG powder samples. From the EDS, it was experimentally confirmed that the existence of all the precursor element like gadolinium, cerium, barium and oxygen found in the initial compounds taken with no other impure elements [20]. Hence the BCG powder prepared through chemical co precipitation method can be used as a good electrolyte powder materials for solid oxide fuel cell applications.

\section{Conclusion}

Gadolinium doped ceria-based BCG electrolyte powder was successfully prepared from co precipitation technique. From DSC thermal analysis, it was understood that the temperature for calcination of the as prepared $\mathrm{BCG}$ powder was $900^{\circ} \mathrm{C}$. The structural analysis confirms the existence of the required fluorite - perovskite structure. The crystallite size for BCG powder was calculated as $38 \mathrm{~nm}$. The crystal structure was identified as cubic fluorite and orthorhombic perovskite phase within BCG structures. From morphological analysis, it was confirmed that the particle size distribution was found to be around $20-50 \mathrm{~nm}$. Hence, the BCG 
nanoparticle with fluorite and perovskite phase will acts as a unsurpassed choice of electrolyte powder for the energy conversion in solid oxide fuel cells (SOFCs).

\section{ACKNOWLEDGEMENT:}

The author thanks the PSG College of Technology management and principal, for generous support to carry out the research work.

\section{References}

[1]O.Yamamote,Y.Arati,Y.Takoda,N.Imanishi,Y.Mizutani,M.Kawai,Y.Nakamura,Solid state Ionics 124,(1995),137.

[2]. C.B.Chowdhary,H.S.Maiti and E.C.Subbarao.in, Solid Electrolytes and their application,New York(1980),49.

[3]. A.S. Kumar, R. Balaji, S. Jayakumar, Mater. Chem. Phys. 202, (2017) 82-88.

[4].M.M.Backo,Material science,Poland,24(2006),39.

[5].G.B.Balags and R.S.Glass,Proc.2nd International symposium on Ionic and Mixed conducting ceramics(1994).

[6].H.Yahiro,K.Eguchi and H.Arai,Solid state Ionics36,(1989),71.

[7].B.C.H.Steele. Solid state Ionics 129 (2000),95

[8].T.Kudo and H.Obayashi,J.Electrochem Sci 123,(1976),415.

[9].H.Yahiro,Y.Eguchi,K.Eguchi and H.Arai,J.Application of Electrochem,18(1988),527.

[10] M.Sahibzada,B.C.H.Steele,K.Hellgardt,D.Barth,A.Effendi,D.Mantzavinos and

I.S.Metcalfe, Chem.Eng.Sci,55, (2000), 3077.

[11].B.C.H.Steele Solid state Ionics (129) 95, (2000) (134) 3.

[12].L.D.Jadhav,S.H.Paewar,M.G.Chourashiya,Bull.Metsa (2007),30,2(97).

[13].U.H.Morri,R.H.Farrell,A.M.Sexton and M.A.Morris J.Phy conf.series,26, (2006),119.

[14]. Y. Zhang, H. Cao, J. Zhang, B. Xia, Jour.of Solid State Ionics, 177, (2006), 3303-3307.

[15]. T. H. Cho, Y. Shiosaki, H. Noguchi, J. Power Sources, 159, (2006), 1322-1327.

[16]. M. J. Godinho, R. F. Gon alvesL, . P. S. Santos, J. A. Varela, E. Longo, E. R. Leite,

Mater. Lett., 61 (2007) 1904-1 907.

[17]. D.S. Vijayan, A. Mohan, J. Revathy, D. Parthiban , R. Varatharajan, "Evaluation of the impact of thermal performance on various building bricks and blocks: A review",

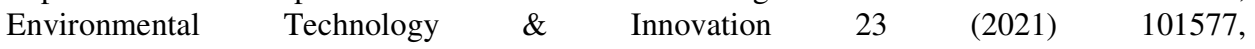
https://doi.org/10.1016/j.eti.2021.101577.

[18]. A. B. Gaikwad, S. C. Navale, V. Samuel, A. V. Murugan, V. Ravi, Mater. Res. Bull., 41 (2006) 347-353. 
[19]. Zhang, Y.; Gao, Z.; Song, N.; Li, X. Electrochimica Acta, 222, (2016),1257-1266.

[20]. G. Xu, X. Zhang, W. He, H. Liu, H. Li, R. I. Boughton, Materials Letters 60 (2006) 962-965. 